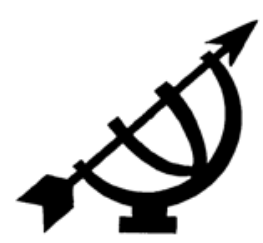

\title{
Taal en kerkeenheid: Calvyn se 1545-Kategismus in Latyn
}

\author{
P.H. Fick \& D. Kotzee \\ Skool vir Kerkwetenskappe \\ Potchefstroomkampus \\ Noordwes-Universiteit \\ POTCHEFSTROOM \\ E-pos: rikus.fick@nwu.ac.za \\ dkotzee@gmail.com
}

\begin{abstract}
Language and church unity: Calvin's 1545 Catechism in Latin

In 1545 Calvin wrote a catechism. He defended the fact that he had done it in Latin, saying: "I judge it useful that there should be public testimonies, whereby churches which, though widely separated by space, agree in the doctrine of Christ, may mutually recognize each other." Although he was constantly being accused by the Roman Catholic Church of being a schismatic, Calvin's ecumenical intentions were above reproach. At every opportunity he stressed the sinfulness of schism from a church that bears the marks of the true church. By the time of the Reformation Latin wasn't regarded any more as a "holy" language, but as a role model for other languages. Although the reformers increasingly propagated the use of the vernacular in religious service, they still maintained correspondence with each other in Latin and wrote many of their treatises in this language. The art of printing presented the same phenomenon: both vernacular and Latin (especially academic works), were produced and distributed. Calvin's "Catechism" of 1545, written in Latin, was soon translated into many languages, even into Greek and Hebrew. Thereby Calvin reached his goal of promoting unity of faith between the different reformation churches. The fact that the catechism was written in Latin gave it a special status as church-historical document: a symbol of Calvin's hope for church unity.
\end{abstract}




\section{Opsomming}

\section{Taal en kerkeenheid: Calvyn se 1545-Kategismus in Latyn}

In 1545 het Calvyn 'n kategismus geskryf. Hy verdedig die feit dat hy dit in Latyn gedoen het soos volg: "Ek is van oordeel dat dit nuttig is dat 'n openlike getuienis na vore kom, waardeur die kerke wat andersins oor lang afstande van mekaar geskei is en tog in Christus 'n eenstemmige leer het, mekaar kan herken." Hoewel hy gedurig uit Rooms-Katolieke oord van kerkskeuring beskuldig is, was sy ekumeniese ingesteldheid bo verdenking. Hy het elke geleentheid aangegryp om die sondigheid van afskeiding van 'n kerk wat die merktekens van 'n ware kerk vertoon, te beklemtoon. Teen die tyd van die Reformasie is Latyn nie meer as 'n "heilige taal" beskou nie, maar eerder as 'n rolmodel vir ander tale. Hoewel die hervormers in toenemende mate die gebruik van die moedertaal vir godsdiensoefening aangemoedig het, het hulle steeds Latyn in hulle korrespondensie met mekaar en in ander geskrifte gebruik. Dit word ook weerspieël in die boekdrukkuns: werke in die verskeie moedertale én in Latyn is gedruk en versprei. Calvyn se "Kategismus" van 1545 in Latyn is spoedig in verskeie tale vertaal - ook in Grieks en Hebreeus. Daarmee het hy sy doel bereik om die eenheid van geloof tussen die reformatoriese kerke te bevorder. Hierdie kerkhistoriese dokument in Latyn verkry sodoende 'n besondere status: 'n simbool van Calvyn se hoop op kerkeenheid.

\section{Inleiding}

Calvyn verdedig in die inleiding van sy Kategismus van 1545 die feit dat hy dit in Latyn skryf. Die eerste rede daarvoor, sê hy, is:

... dat ek van oordeel is dat in so 'n verwarde en verspreide toestand van die Christene, dit nuttig is dat 'n openlike getuienis na vore kom, waardeur die kerke wat andersins oor lang afstande van mekaar geskei is en tog in Christus 'n eenstemmige leer het, mekaar kan herken. 1

Calvyn het hierdie doel bereik. Beza noem hierdie kategismus "'n verbasende werk", 2 juis omdat dit spoedig nie alleen in Duits,

1 Primum in hoc confuso dissipatoque christiani nominis statu, utile esse iudicio, exstare publica testimonia, quibus ecclesiae, quae longis alioqui locorum spatiis dissitae consentiem habent in Christo doctrinam, se mutuo agnoscant. (CO 6,67.) 
Engels, Skots, Nederlands en Spaans vertaal is nie, maar ook in Hebreeus en Grieks.

Soos Luther het Calvyn ook op twee aspekte van die kerk gewys: die sigbare en die onsigbare, geestelike. Luther het laasgenoemde egter so oorbeklemtoon dat hy nooit uitgekom het by Calvyn se helder en praktiese ekumeniese ingesteldheid nie. Soos Augustinus en Wycliff sien Calvyn die oorsprong van die kerk in die verborge verkiesing van God (McNeill, 1959:1-2). Kerkeenheid was vir Calvyn egter ook gegrond op unitas fidei 3 (eenheid van geloof), consensus fidei (eenstemmigheid in die geloof; $\mathrm{CO}$ 6,6-7) en die unitas veritatis $^{4}$ (eenheid in waarheid). Deur die verspreiding van die Kategismus was dit sy wens dat hierdie eenheid bevorder sou word.

In die lig van die hedendaagse belangstelling op ekumene, is die klem wat Calvyn op kerkeenheid plaas, weer aktueel. Die doel van hierdie artikel is om te bepaal wat die besondere status van die Kategismus van 1545 as kerkhistoriese dokument gehad het. Dit word gedoen deur eers te bepaal wat kerkeenheid vir Calvyn ingehou het en tweedens watter kommunikatiewe rol Latyn tydens die Reformasie gespeel het.

\section{Calvyn oor die eenheid van die kerk}

Uit Rooms-Katolieke oord het talle beskuldigings teen die hervormers gekom. Daar was persoonlike aanvalle, $\mathbf{5}$ soos dat hulle geen ander doel voor oë gehad het nie as om hulle eie ydelheid en hebsug te bevredig 6 en dat hulle listige mense was wat openlik en in die geheim 'n verderflike invloed op die samelewing in die breë gehad het. 7 Daar was ook die beskuldiging dat hulle onder die

3 Hierdie term gebruik hy in die heel eerste sin van die inleiding tot die Kategismus van 1545 (CO 6,6-7).

4 'n Term wat hy byvoorbeeld in sy kommentaar op Romeine 16:17 gebruik (CO 49,288). Hy wys daarop hoe hierdie waarheidseenheid deur die "gesante van Satan" in kerke in gevaar gestel word wanneer hulle onmin saai.

$5 \quad$ In hierdie verband word grootliks gebruik gemaak van Calvyn se Responsio op Sadoletus se brief.

6 "Itaque nihil aliud fuisse nobis propositum cavillaris, nisi ut ambitionem et avaritiam expleremus." (CO 5,388.)

7 "Homines astutos vocas ... publice privatimque perniciosos universae hominum societati" (CO 5,390). 
gesag van die pous wou uitkom om "hulleself vry te stel met die oog op onbeteuelde ongebondenheid" 8 sonder om aan die oordeel van God te dink. Calvyn se antwoord op hierdie beskuldiging van bandeloosheid was dat "dit juis noodsaaklik is dat die liggaam van die kerk, om goed saamgevoeg te wees, soos met senings deur dissipline saamgebind moet word". 9

Uit Rooms-Katolieke oord is die Reformasie ook dikwels voorgehou as 'n defectio ab ecclesia (afvalligheid van die kerk; CO 5,388), 'n discessio ab ecclesia (afskeiding van die kerk; CO 5,391), of 'n defectio a veritate Dei (afvalligheid van die waarheid van God; CO 5,391 ). Hierdie afskeiding van die kerk beteken ook per se, volgens die vyande van die Reformasie, 'n wegbeweeg van die oorgeërfde dogma. Daarom word die hervormers ook repertores novorum dogmatum (uitvinders van nuwe dogmas; CO 5,393) genoem. Kardinaal Sadoletus het so ver gegaan om die hervormers daarvan te beskuldig dat wat ook al die destydse afgelope 1500 jaar of langer goedgekeur was met die gemeenskaplike instemming van die gelowiges, onbeskaamd deur hulle uitmekaar geskeur en vernietig is. 10 Hy het ook nie geskroom om die hervormers se leer 'n "groot mengelmoes van goddelose dogmas" 11 te noem nie.

Calvyn vat hierdie beskuldigings saam wanneer hy sê: "Hulle het my van die twee ergste oortredings beskuldig: kettery en skeurmakery". 12 Op hierdie beskuldigings was Calvyn se antwoord in gebedsvorm:

By wie die blaam nou eintlik lê, is vir $U$ om te besluit, o Here. Wat my betref, ek het nog altyd in woord en daad bewys gelewer hoeveel ek my beywer het vir eenheid. Vir my was dit

$8 \quad$ “... ut nos in effrenem licentiam solveremus ..." (CO 5,406).

9 "Disciplinam enim, non secus ac nervis, corpus ecclesiae, ut bene cohaereat, necesse est colligari". (CO 5,406-407.)

10 "... quaecunque ab annis mille quingentis, aut amplius, constanti fidelium consensu sunt comprobata, ea nostra importunitate convelli et abrogari" (CO 5,394).

11 “... magnam impiorum dogmatum farraginem ...” (OC 5,388).

12 "Duobus maximis criminibus, reum me fecerunt, haereseos et schismatis." (CO 5,408.) 
egter ' $n$ eenheid van die kerk wat by $U$ begin en by $U$ moet eindig. 13

Sy passie vir kerkeenheid blyk ook uit die wyse waarop hy sy Responsio aan Sadoletus afsluit:

Die Here gee, Sadoletus, dat jy en al die res van jou mense uiteindelik besef dat daar geen ander band vir kerklike eenheid is nie as dat die Here Christus, wat ons met God die Vader versoen het, ons vanuit die verstrooiing in die gemeenskap van sy liggaam terugbring; sodat ons, deur sy een Woord en Gees ons verenig in een hart en siel. 14

Die middeleeuse kerk het egter so korrup geraak dat reformasie onafwendbaar geword het. Calvyn beskryf die leer, dissipline, sakramente en seremonies daarvan as ' $n$ ruïne in vergelyking met die kerk in die tyd van die vroeë kerkvaders (CO 5,394). Die skolastiese teologie van sy tyd noem hy 'n quaedam arcanae magiae species ('n soort geheime towerkuns; CO 5,396). "Valse profete het die ou kerk ontstig", sê hy, "ons moet dieselfde verwag". 15 Uiteindelik het die wegbreek van die kerk 'n necessitas geword wat geleë was in die feit dat "die lig van die goddelike waarheid uitgedoof, die Woord van God begrawe, die verdienste van Christus in diepe vergetelheid gelaat en die pastorale diens omver gewerp is". 16

Die inhoud en omvang van Calvyn se korrespondensie spreek ook van sy ekumeniese ingesteldheid. Dit het gestrek tot die verste grense van die Europese protestantisme: van Skandinawië tot Italië, van Engeland tot Rusland (Nijenhuis, 1959:10). In 'n brief wat hy in

13 "Verum penes quos sit culpa, tuum est nunc pronunciare, o Domine. Ego semper et verbis et factis testatus sum, quanto unitatis studio tenerer. Verum illa mihi erat ecclesiae unitas, quae abs te inciperet, ac in te desineret." (CO 5,409.)

14 "Faxit Dominus, Sadolete, ut tu ac reliqui omnes tui aliquando intelligatis, non aliud esse ecclesiasticae unitatis vinculum, quam Christus Dominus, qui nos Deo patri reconciliavit, in corporis sui societatem nos ab ista dissipatione recolligat: ut ita uno eius verbo ac spiritu in cor unum et animam unam coalescamus." (CO 5,416.)

15 “... pseudoprophetae veterem ecclesiam turbarunt, idem et nobis expectandum est" (OC 55,459).

16 "Ista porro fuit necessitas, quod lux divinae veritatis exstincta, sepultum Dei verbum, virtus Christi profunda oblivione inducta, munus pastorale inversum erat." (CO 5,402-403.) 
1552 vanuit Genève aan Cranmer skryf, lees 'n mens byvoorbeeld die bekende woorde:

Dit is so dat as die ledemate verwyder word, dan lê die liggaam van die kerk verskeurd. In so 'n mate raak dit my, dat, indien dit sou blyk dat iemand my nodig het, dit my inderdaad nie enige ongerief sou veroorsaak om, as dit nodig is, as gevolg daarvan tien oseane te oorkruis nie. 17

Dit was egter nie vir hom 'n eenheid ten alle koste nie. In sy kommentaar op 1 Petrus 2:1 sê hy iets wat die kern vorm van sy oortuigings oor kerkeenheid: "Immers, die band van heilige eenheid is eenvoudig die waarheid van God. Die oomblik as daarvan afgewyk word, bly niks anders as verskriklike verdeeldheid oor nie". 18 Om hierdie rede het Calvyn ook sterk standpunt ingeneem teen die Anabaptiste, Spiritualiste en Anti-Trinitariërs (Nijenhuis, 1959:253-272; Balke, 1977:1-4).

In sy kommentaar op Jeremia 31:7 beskuldig hy die Papiste daarvan dat hulle ook op eensgesindheid roem, maar "intussen gaan hulle verby dit wat die eerste plek behoort te beklee, dit is naamlik dat almal moet ag slaan op die een God, soos wat hulle deur sy Woord geleer word". 19 In sy kommentaar op die gelykenis van die herder en sy skape in Johannes 10, sê Calvyn dat hulle wat afdwaal agter vals lering aan, ophou om skape genoem te word. Hy bring dit in verband met die uitverkiesing wanneer hy sê dat Christus wil hê dat "al die uitverkorenes van God, hoewel hulle op ontelbare maniere versoek word om af te dwaal, in gehoorsaamheid aan die suiwere geloof bewaar word". 20

Ciprianus van Kartago het 'n groot invloed op Calvyn se ontwikkeling van die leer oor die kerk gehad (Mooi, 1965:205). In sy

17 "Ita fit, ut membris dissipatis, lacerum iaceat ecclessiae corpus. Quantum ad me attinet, si quis mei usus fore videbatur, ne decem quidem maria, si opus, sit, ob eam rem traiicere pigeat." (CO 14,314.)

18 "Vinculum enim sanctae unitatis simplex est Dei veritas: simul atque ab ea disceditur, nihil aliud restat quam horrenda dissipatio." (CO 5,460.)

19 "... sed interea praetermittunt quod debebat tenere primum gradum, nempe ut omnes in Deum unum respiciant, quemadmodum edocti sunt eius verbo" (CO 38,649).

20 “... omnes Dei electos, etiamsi innumeris erroribus tentati fuerint, in purae fidei obedientia retentos esse" (CO 47,239). 
Institusie 4.1.1 (CO 2,746) en 4.2.6 (CO 2,772) gebruik Calvyn Ciprianus se beeld van die kerk as moeder, ${ }^{21}$ die beeld van die een son met baie strale en van die boom met sy een stam en baie takke. 22 In sy De Scandalis van 1550 skryf Calvyn oor die wantoestande in die Rooms-Katolieke Kerk van sy tyd. Hy beroep hom egter nie in die eerste plek op die outoriteit van die vaders om die wantoestande uit te wys nie. Hy vind die deurslag in die opdragte van Christus; 'n beoordelingsbeginsel, sê hy, wat al deur Ciprianus gestel is. 23 In sy Institusie 4.1 .10 (CO 2,754) waarsku hy dat indien iemand sonder goeie rede die kerk verlaat, so 'n person God en Christus verloën. Diegene wat egter in Christus glo, loop nie gevaar om die kerk te skeur nie; "in Christus is die band van eenheid" te vind. 24 In sy kommentaar op Esegiël 13:9 belig hy die eenheid van die kerk in Christus vanuit 'n ander hoek: Christus is die Hoof van sy kerk en Hy "wil nie en kan nie van sy kerk losgeskeur word aan wie Hy verbind is in 'n onlosmaaklike verbintenis soos wat die hoof aan die liggaam verbind is nie". 25 Hy sê die logiese gevolg wanneer 'n mens nie die eenheid met die gelowiges beoefen nie, is dat jy van Christus afgesny word.

Benewens die beelde van Ciprianus wat Calvyn gebruik om die eenheid van die kerk te beskryf, span hy ook sy eie beelde in om dit te doen. Verskeie dele van die kerk word byeengebring soos in 'n simfonie. Daar is 'n verskeidenheid klanke, maar hulle word in sulke proporsies bymekaar gebring dat dit 'n harmonie (concertum) tot gevolg het. 26 'n Kerk-in-eenheid is soos 'n liggaam waarvan die

21 Kyk Ciprianus (6: "Habere iam non potest Deum patrem, qui ecclesiam non habet matrem"; PL 4:503). Hy gebruik ook in Hoofstuk 7 van hierdie werk, na aanleiding van Johannes 19:23-24, die beeld van die naatlose kleed van Christus om die eenheid van die kerk te beskryf (Ciprianus, PL 4:504).

22 Kyk Ciprianus (5; PL 4:501-502)

23 "Plausibilis olim erat illa Cypriani sententia: Non spectandum quid ante nos alli fecerint aut dixerint, sed quod mandavit Christus ..." (CR 8,77).

24 Sy kommentaar op Matteus 24:28: “... in ipso Christo unitatis vinculum ..." (CO 45,665).

25 "Christus autem non vult nec potest divelli a sua ecclesia, cum qua coniunctus est nodo insolubili, ut caput cum corpora." (CO 49,281.)

26 Sy kommentaar op 1 Korintiërs 12:4: “... sicuti in symphonia varii sunt cantus, sed tali proportione inter se tempterati, utunum efficiant concentum" (CO 49,497). 
verskillende dele in harmonie saamgevoeg is. In sy kommentaar op 1 Korintiërs 14:36 sluit hy aan by die beeld van vriendskap:

... want geen kerk behoort elkeen op sy eie met sigself ingenome te wees nie: maar almal behoort op hulle beurt die regterhand na mekaar uit te steek om die gemeenskap tussen hulle te koester, en in soverre as wat die belang van eensgesindheid dit vereis, behoort die een die ander in ag te neem. 27

Soos Augustinus het hy dit egter beklemtoon dat daar nie 'n volmaakte kerk bestaan nie en dat die heilige dorsvloer van God nie heeltemal skoongemaak sal word voor die laaste dag nie. $28 \mathrm{Hy}$ verwys in sy kommentaar op Psalm 15:1 op die Donatiste van ouds en die Anabaptiste van sy tyd wat "van mening is dat 'n kerk wat oortredings verdra, nie 'n ware kerk is nie". 29 Hieroor sê hy: "... solank as wat die godsdiens suiwer bly voortbestaan wat die leer en aanbidding betref, behoort ons nie so ontstig te word deur die oortredings van mense dat ons as gevolg daarvan die eenheid van die kerk verskeur nie". $30 \mathrm{Hy}$ is daarvan oortuig dat die kerk se heiligheid onvolmaak maar progressief is. Vooruitgang na volmaaktheid toe en die beoefening van onderlinge liefde en vergifnis in hierdie bedeling van onvolmaaktheid is karaktertrekke van die ware, sigbare kerk. In die Institusie (4.1.16) voeg hy hom weereens by Augustinus wat waarsku dat daar met medelye omgegaan moet word met die gebreke van mense. Dit is soms nodig om daaroor te sug en te treur "totdat God dit óf regstel óf totdat Hy die onkruid in die oes uitroei en die kaf uitwaai". 31

Ten slotte is dit hier van besondere belang om daarop te let dat Calvyn in sy Kategismus die kinders oor kerkeenheid onderrig.

27 “... nulla enim Ecclesia sibi privatim addicta esse debet, aliis neglectis: sed debent omnes potius dextras invicem porrigere, ut communionem inter se foveant, et quatenus postulat concordiae ratio, aliae aliis se accommodare" (CO 49,533).

28 Vir Augustinus se oortuigings oor volmaaktheid in die kerk, kyk Markus (1990:65).

29 "Quia non putant veram esse ecclesiam, quae vitia tolerat." (CO 30,143.)

30 "... modo pura religio quoad doctrinam et ritus vigeat, hominum delictis non ita nos offendi convenit, ut propterea scindamus unitatem" (CO 30,143).

31 “... donec aut emendet Deus ac corrigat, aut in messe eradicet zizania, et paleas ventilet" (CO 2,759). 
Wanneer die leermeester vra: "Waarom verbind jy vergiffenis van sonde aan die kerk?", moet die student antwoord: "Omdat niemand dit verkry wat nie vooraf met die volk van God verenig is en die eenheid met die liggaam van Christus volhardend tot die einde toe bevorder en sodoende getuienis daarvan lewer dat hy ware lid maat van die kerk is nie." En op die leermeester se stelling: "Volgens hierdie redenasie stel jy dat daar buite die kerk niks anders as verdoemenis en verderf is nie", moet die student soos volg reageer: "Volkome so ja. Want hulle wat van die liggaam van Christus wegbreek en met sektes die eenheid daarvan verskeur, vir hulle word alle hoop op saligheid ontneem solank as wat hulle in 'n afvalligheid van so 'n aard bly." 32

\section{Latyn en kerkeenheid}

In die Middeleeue het die Kerk en die akademie 'n onversadigbare behoefte gehad aan mense wat bekwaam was in Latyn - die lingua franca van daardie tyd. Teen die helfte van die vyftiende eeu het die situasie egter drasties verander. 'n Toenemende belangstelling in die "wêreld daarbuite" het ontdekkingsreisigers al hoe meer in aanraking gebring met onbekende volke en hulle eiesoortige tale.

Die herontdekking van die Antieke, Klassieke kultuur wat hiermee gepaard gegaan het, het 'n interessante nuwe status vir Latyn meegebring. Die nuutontdekte Latyn van Cicero het die middeleeuse Latyn baie lomp en stylloos laat voorkom en daarby die besef gebring dat ook Latyn 'n ontwikkelingsgeskiedenis gehad het en onderworpe was aan die grille van tyd en menslike aktiwiteite. Noudat Latyn nie meer beskou is as verhewe bo en kwalitatief verskillend van ander tale (en selfs 'n "heilige taal") nie, maar 'n taal wat slegs 'n mate van verskil en ander historiese omstandighede as die ander gehad het, het dit 'n nuwe verwantskap met hierdie ander tale gekry: dié van 'n rolmodel. As Cicero se harde werk Latyn tot byna volmaaktheid gebring het, wie was dan die Cicero van Duits, Engels of Nederlands (Law, 2003:232)?

32 "M: Cur peccatorum remissionem subnectis ecclesiae? P: Quia eam nemo consequitur, quin et coadunatus fuerit ante populo Dei, et unitatem cum Christi corpore perseveranter ad finem usque colat: eoque modo testatum faciat, verum se esse ecclesiae membrum. M: Hac ratione constituis, extra ecclesiam non nisi damnationem et extium esse. P: Omnino. Quienim discessionem faciunt a Christi corpore, factionibusque scindunt eius unitatem, iis spes omnis salutis praesisa est, quantisper manent in eiusmodi dissidio." (CO 6,42.) 
Dit kom daarom byna as 'n teenstrydigheid voor dat die Reformasie, wat soveel klem geplaas het op die toenemende gebruik van die verskillende moedertale, juis moontlik gemaak is deur ' $n$ beweging (die Renaissance-humanisme) wat gekenmerk is deur die gebruik van Latyn (Collinson, 2003:29).

Hierdie eienaardige verhouding tussen Latyn en die verskillende moedertale word verder duidelik met die ontdekking van die boekdrukkuns. Die toenemende gebruik daarvan het 'n groot invloed op die laat-middeleeuse geestelike lewe gehad. Vanaf ongeveer 1490 het die druk van geestelike werke in moedertaalvorm geweldig toegeneem. Tog is die internasionale Latynse geleerdheidskultuur steeds deur die boekdrukkuns in stand gehou. Kommunikasie het nou vinniger en meer wydverspreid plaasgevind as gevolg van die reproduksie van dokumente. Die beskikbaarheid en stabiliteit van gedrukte tekste het internasionale debatte tussen geleerdes vergemaklik en ou tekste en outeurs weer laat herlewe (Pettegree, 2002:21).

Die hervormers, veral Luther en Calvyn, het egter self 'n deeglike skool- en universiteitsopleiding gehad waarvan die onderrig in en die gebruik van Latyn 'n integrale deel gevorm het. As 'n regstudent het Calvyn 'n deeglike voorbereidende onderrig in Latyn ontvang, aangesien Teologie, Medies en Regte net in Latyn aangebied is. Dit is in elk geval duidelik uit Calvyn se geskrifte dat hy uiters vaardig was in die gebruik van Latyn. Hy het Mathurin Cordier, sy leermeester in Latyn aan die Universiteit van Parys, vereer deur sy kommentaar van 1 Tessalonisense in 1550 aan hom op te dra. Hy sluit dié huldigingsbrief soos volg af: "En ek wou gehad het dat dit as 'n getuienis vir die nageslag sou wees, dat as daar enige voordeel vir hulle uit my geskrifte sou kom, hulle sal weet dat dit in 'n mate by jou sy oorsprong het". 33 Genève het boonop, onder invloed van Calvyn en Beza, in 1559 'n Latynskool en 'n Akademie gestig (Maag, 2002:537). Die einste Cordier het sy laaste lewensjare as professor in hierdie akademie gedien (Van 't Veer, 1942:100).

Die hervormers het steeds Latyn gebruik om aan mekaar te skryf. So was hulle in staat om hulle idees en oortuigings aan mekaar te kommunikeer en 'n geestelike broederskap te vorm wat van Genève tot Aberdeen gestrek het. Die Reformasie sou heelwat stadiger ge-

33 "Atque hoc posteris testatum esse volui, ut si qua ex meis scriptis ad eos perveniet utilitas, aliqua ex parte abs te manasse agnoscant." (CO 13,526.) 
vorder het as dit nie vir hierdie tipe kommunikasie was nie (Weir, 1990:1-2). Dit geld uiteraard ook vir die verspreiding van die Reformasie op alle vlakke. 'n Goeie voorbeeld hiervan vind 'n mens in 'n brief wat Calvyn in 1553 aan 'n onbekende dame in Italië skryf. Hy begin sy brief so:

Alhoewel ek geweet het, edele dame, dat $u$ 'n vertaler nodig gaan hê om my skrywe te verstaan, het van my vriende my aangemoedig om te skryf: om die waarheid te sê, hulle het my geweldig aangemoedig om hierdie taak uit te voer. Ek het vir hierdie doel eerder die Latynse taal verkies, omdat ek gehoop het dat daar baie mense byderhand sou wees wat dit in Italiaans sou kon vertaal, aangesien daar óf geen kennis van die Franse taal by u-hulle is nie óf dat dit skaars is. $\mathbf{3 4}$

Latyn en moedertaal was vir ' $n$ hele tyd lank bykans in 'n spanningsveld vasgevang wat die Reformasie betref. Die indruk wat Le Fèvre d'Etaples se 1525-vertaling van die Bybel in die Franse taal op Calvyn gehad het, kan byvoorbeeld duidelik afgelei word uit sy vurige pleidooie vir moedertaalgodsdiens - en dit ten spyte daarvan dat sy eie werke grootliks in Latyn geskrywe is (Simpson, 1981:6). Die hervormers was oor die algemeen daarvan oortuig dat die boodskap van die evangelie bedoel is om deur almal verstaan te word en nie versluier moet word deur 'n onverstaanbare taal en rituele nie. Calvyn dring byvoorbeeld ernstig daarop aan dat daar in populari sermone (openbare gebede) in die moedertaal gebid moet word, anders kan dit nie tot stigting van die kerk gedoen word nie. 35 'n Mens kry 'n goeie beeld van die verhouding tussen Latyn en die moedertaal deur kennis te neem van 'n lys gesensureerde reformatoriese geskrifte wat in 1542 deur die Fakulteit Teologie van die Universiteit van Parys uitgegee is. Van die 65 titels op die lys was 22 in Latyn en 43 in Frans. Dit kan met sekerheid gesê word dat 36 van hierdie geskrifte hulle oorsprong in Genève gehad het (McGrath, 1999:237).

Tog was Calvyn deeglik daarvan bewus dat om Latyn geheel en al van die tafel te vee dwaas sou wees, omdat daar soveel werke in

34 "Quandam sciebam opus fore interprete, generosa Domina, ut literas meas intellegeres, scribendi tamen fiduciam mihi dederunt quidam amici: imo ad hoc officium tibi praestandum vehementer hortati sunt. Linguam vero latinam potius elegi, quia sperabam tibi multos fore ad manum, qui Italice exponerent, quum linguae Gallicae nulla fere vel rara sit apud vos cognitio." (CO 14,739.) 
Latyn bestaan het wat tot groot stigting gelees kon word. Hy dra sy kommentare op Galasiërs, Efesiërs, Filippense en Kolossense aan Prins Christofer op. In die huldigingsbrief aan hom verwys hy na die feit dat die prins 'n deeglike opleiding in Latyn gehad het en dat dit hom in staat stel om in sy vrye tyd godsdienstige boeke te lees waarby hy baie kan baat, juis in 'n onstuimige tyd waarin die lees van sulke werke tot groot troos kan wees. ${ }^{36}$

Die feit dat Calvyn sy Kategismus in Latyn skryf, bly egter enigmaties. As "onderwysing" toon sy Institusie ander kenmerke as die Kategismus. Die Institusie is besondere volwasse "onderwysing" wat in die eerste plek daarop gerig is om die ware leer oor te dra, terwyl die Kategismus gerig is op die onderwysing van die verbondsjeug. Verwysings in die Kategismus is daarom hoofsaaklik uit die Bybel geneem, terwyl die Institusie ryklik put uit die kerkvaders en selfs nie-Christelike outeurs. Hieruit blyk dit dat Calvyn met sy Institusie ook die student van die Humanisme en Skolastiek wil bereik. Die Institusie se voorwoord aan koning Frans I verteenwoordig die apologetiese aspek van die Institusie. Hierin is Calvyn die advokaat aan die woord, en sy opleiding as regsgeleerde in Bourges en Orléans skemer duidelik deur (Simpson, 1981:6). In 1560 gee Calvyn sy Institusie in Frans uit. In die Inleiding daarvan verduidelik hy dit soos volg: "Ek het dit eers in Latyn geskryf om tot diens te wees aan alle geleerdes, aan watter volk hulle ookal behoort; toe, agterna, het ek dit in ons eie taal vertaal omdat dit my begeerte is om dit te kommunikeer wat tot vrug vir ons Franse volk kan wees." 37 Dit bevestig die feit dat die Institusie in Latyn 'n akademiese en juridiese status gehad het wat as't ware die skryf daarvan in Latyn regverdig.

Dit is egter nie die geval met sy Kategismus nie. Calvyn het vir die eerste keer ' $n$ kort kategismus in 1536 uitgegee en weer een in 1541 saamgestel - hierdie keer in die vorm van vrae en antwoorde. Hierdie werke het hy in Frans geskryf. Laasgenoemde kategismus gee hy, met kleiner veranderings, in 1545 uit. Hierdie keer doen hy dit in Latyn. Dit is egter duidelik dat hy dit nie, soos die geval met die Institusie, om akademiese of juridiese redes doen nie, maar eerder

36 Kyk brief 994 (CO 12,658-659).

37 "Et premierement l'ay mis en latin: a ce qu'il peust servir a toutes gens d'estude, de quelque nation qu'ilz feusent: puis apres desiderant de communiquer ce qui en pouoit venir de fruict a nostre Nation Francoise: l'ay aussi translaté en nostre langue." (CO 3,23.) 
om simboliese redes. Deur dit in Latyn te skryf, gee hy 'n besondere status daaraan. Hierdie dokument in Latyn is nie in die eerste plek bedoel as 'n actus instruendi ('n onderrigshandeling) nie, maar 'n publica testimonia unitatis fidei ('n openlike getuienis van die eenheid van geloof). Dit dien as 'n simbool van kerkeenheid; oorspronklik bedoel (wat die inhoud betref) vir die onderrig van kinders en uiteindelik in vertaalde vorm weer bedoel vir kinders, maar in die Latynse vorm juis nié in die eerste plek vir kinders bedoel is nie. $\mathbf{3 8}$ Uiteindelik gee dit aan die dokument as 't ware 'n konfessionele status, 'n demonstrasie van sy geloof aan die gemeenskap van die gelowiges.

\section{Slot}

Vanuit Genève het Calvyn die ontstuimigheid van die kerk in Europa gesien, maar steeds vurig gehoop op eenheid binne die reformatoriese beweging. Daar was egter min ander figure wat hierdie hoop met dieselfde intensiteit as Calvyn gekoester en dit probeer verwerklik het. Die Protestante was oor die algemeen te vasgevang in hulle plaaslike probleme en in die vasstelling en verdediging van hulle eie leerstellings. Hulle was ook geneig om hierdie leerstellings as voorwaardes vir geestelike omgang en onderlinge bande te beskou.

Calvyn se hoop op eenheid is nooit vervul nie. Tog het dit nie afgeneem nie. In die heel laaste brief wat hy voor sy dood geskryf het, beskryf hy sy innige vriendskap en verbintenis met Farel as iets wat "nuttig vir die kerk van God was en wat vir ons ook in die hemel vrug sal bring". 39 Sy Kategismus van 1545, geskryf in Latyn, staan as 'n monument vir hierdie hoop op kerkeenheid in 'n uiters ontstuimige tyd. daarvoor geskryf nie. 


\section{Geraadpleegde bronne}

BALKE, W. 1977. Calvijn en de doperse radikalen. Amsterdam: Ton Bolland.

CALVIN, J. 1863-1900[1531-1564]. Ioannis Calvini Opera Quae Supersunt Omnia, Vol. I-LIX. Ediderunt G[W]. Baum, E. Cunitz \& E. Reuss. Vol. I-LIX, in Corpus Reformatorum, Vol. XXIX-LXXXVII. Brunsvigae/Berolini: C.A. Schwetschke et filium. [= CO 1-59.]

CIPRIANUS. CYPRIANUS CARTHAGINIENSIS. De unitate ecclesiae. Turnhout: Brepols. (PL 4:494-520.) $\mathbf{4 0}$

$\mathrm{CO}$

kyk CALVIN, J. 1863-1900 [1531-1564]

COETZEE, C.F.C. 2006. Calvyn en die eenheid van die kerk. Acta theologica, 26(1):16-35.

COLLINSON, P. 2003. The reformation. London: Phoenix.

D'ASSONVILLE, V.E. 1974. Calvyn verdedig sy stad. Potchefstroom: Pro Rege.

LAW, V. 2003. The history of linguistics in Europe: from Plato to 1600. Cambridge: University Press.

MAAG, K. 2002. Education and literacy. (In Pettegree, A., ed. The reformation world. London: Routledge.)

MARKUS, R. 1990. The end of ancient Christianity. Cambridge: Cambridge University Press.

McGRATH, A.E. 1999. Reformation thought: an introduction. Oxford: Blackwell.

McNEILL, J.T. 1959. Calvin as an ecumenical churchman. Paper presented at the Calvin Anniversary Lectures at Calvin College, 23 Oct. (Unpublished.)

MOOI, R.J. 1965. Het kerk- en dogmahistorisch element in de werken van Johannes Calvijn. Wageningen: Veenman.

NIJENHUIS, W. 1959. Calvinus oecumenicus: Calvijn en de eenheid der kerk in het licht van zijn briefwisseling. Gravenhage: Nijhoff.

OLIN, J.C., ed. 1966. John Calvin and Jacopo Sadoleto: a reformation debate. New York: Harper Torchbooks.

PETTEGREE, A., ed. 2002. The reformation world. London: Routledge.

SIMPSON, H.W. 1981. Die aard van die Institusie van Calvyn. Die Kerkblad, 84(2611):6.

VAN 'T VEER, M.B. 1942. Catechese en catechetiese stof by Calvyn. Kampen: Kok. (Proefskrif, Vrije Universiteit.)

WEIR, D.A. 1990. The origins of federal theology in sixteenth century reformation thought. Oxford: Clarendon.

\section{Kernbegrippe:}

\section{Calvyn}

kategismus

kerkeenheid

Latyn

40 PL: "Patrologia cursus completus omnium ss. patrum, doctorum, scriptorumque ecclesiasticorum Latinorum." 
Key concepts:

Calvin

catechism

church unity

Latin 
